\title{
The future of COVID-19 in Nepal: A two-week time series analysis of the confirmed cases
}

\author{
Viswa C. Chandu ${ }^{1}$
}

AFFILIATION

1 Department of Public Health Dentistry, SIBAR Institute of Dental Sciences, Andhra Pradesh, India

CORRESPONDENCE TO

Viswa C. Chandu. Department of Public Health Dentistry, SIBAR Institute of Dental Sciences, Takkellapadu, Guntur, Andhra Pradesh, 522509, India. E-mail: viswachaitanya17@gmail.com ORCID ID: https://orcid.org/0000-0002-5284-4032

Popul. Med. 2020;2(July):20

\section{KEYWORDS}

time series analysis, COVID-19, South-East Asia

Received: 22 May 2020, Accepted: 14 June 2020

https://doi.org/10.18332/popmed/123942

\section{Dear Editor,}

It is established far beyond doubt by now that there is hardly any nation in the world which escaped the Coronavirus disease (COVID-19) pandemic ${ }^{1}$. This global health crisis of severe magnitude pushed the world into a plethora of uncertainties. Most of the nations across the world adopted non-pharmaceutical interventions like encouragement of personal hygiene, social distancing, and implementation of restrictive measures in light of the non-availability of disease specific preventive or curative care yet. However, these measures have a significant impact on the economies of developing nations. The WHO regional director for SouthEast Asia, P. K. Singh, addressed the need for these countries to find strategic plans to lift the restrictive measures in a graded manner based on empirical evidence ${ }^{2}$. It has been advised by WHO to consider lifting the control measures only after achieving control in the transmission of the disease. In this context, it is very important for countries to forecast the possible growth in the number of COVID-19 confirmed cases in the near future so as to act in an informed manner.

We performed a time series analysis for forecasting the number of confirmed COVID-19 cases in Nepal in the near future of two weeks' time. Previous data on the number of COVID-19 cases in Nepal from 18 April to 19 May 2020 were collected from the WHO COVID-19 situation reports ${ }^{3}$.
IBM SPSS verison 20.0 software was used in the time series forecasting. To determine the best fitting model for the time series data of number of confirmed COVID-19 cases in Nepal over the past one month, we used the Expert Modeler feature in the SPSS time series analysis. The modeler suggested ARIMA $(0,1,0)$ to be the best fitting model for the time series data at hand. ARIMA is a leading model in time series forecasting, which utilizes the memory of previous data (AR - autoregressive component), stationarizes the data in the time series ( I - integrated component), and accounts for the previous error terms (MA - moving average component). The values of AR, I, and MA are defined as $p, d$, $q$, respectively, in the ARIMA (p, d, q) model. ARIMA $(0,1,0)$ selected by the Expert Modeler feature, after considering the nature of data and applying first order differencing to make it stationary, was used to predict the number of COVID-19 confirmed cases in Nepal in the near future (i.e. till 2 June 2020). The model statistics and parameters are presented in Table 1. Figure 1 shows the autocorrelation function (ACF) and partial autocorrelation functions (PACF) of the residuals of ARIMA $(0,1,0)$. A graphical representation of the time series forecasting is presented in Figure 2. According to the study, the point forecast of number of cases by 2 June 2020 in Nepal would be 1266 (95\% CI: 5292602). Figure 3 shows a comparison between the model

Table 1. ARIMA $(0,1,0)$ model statistics and parameters

\begin{tabular}{|c|c|c|c|c|c|}
\hline ARIMA $(0,1,0)$ & & $\mathbf{R}^{2}$ & Normalized BIC & \multicolumn{2}{|c|}{ Ljung-Box Q (18) statistic (df); p } \\
\hline model statistics & & 0.977 & 5.52 & \multicolumn{2}{|c|}{$17.67(18) ; 0.477$} \\
\hline ARIMA $(0,1,0)$ & & Estimate & S.E. & $t$ & $\mathbf{p}$ \\
\hline \multirow[t]{2}{*}{ model parameters } & Constant & 0.081 & 0.019 & 4.35 & 0.0001 \\
\hline & Difference & 1 & & & \\
\hline
\end{tabular}


Figure 1. ACF and PACF of the residuals of ARIMA $(0,1,0)$

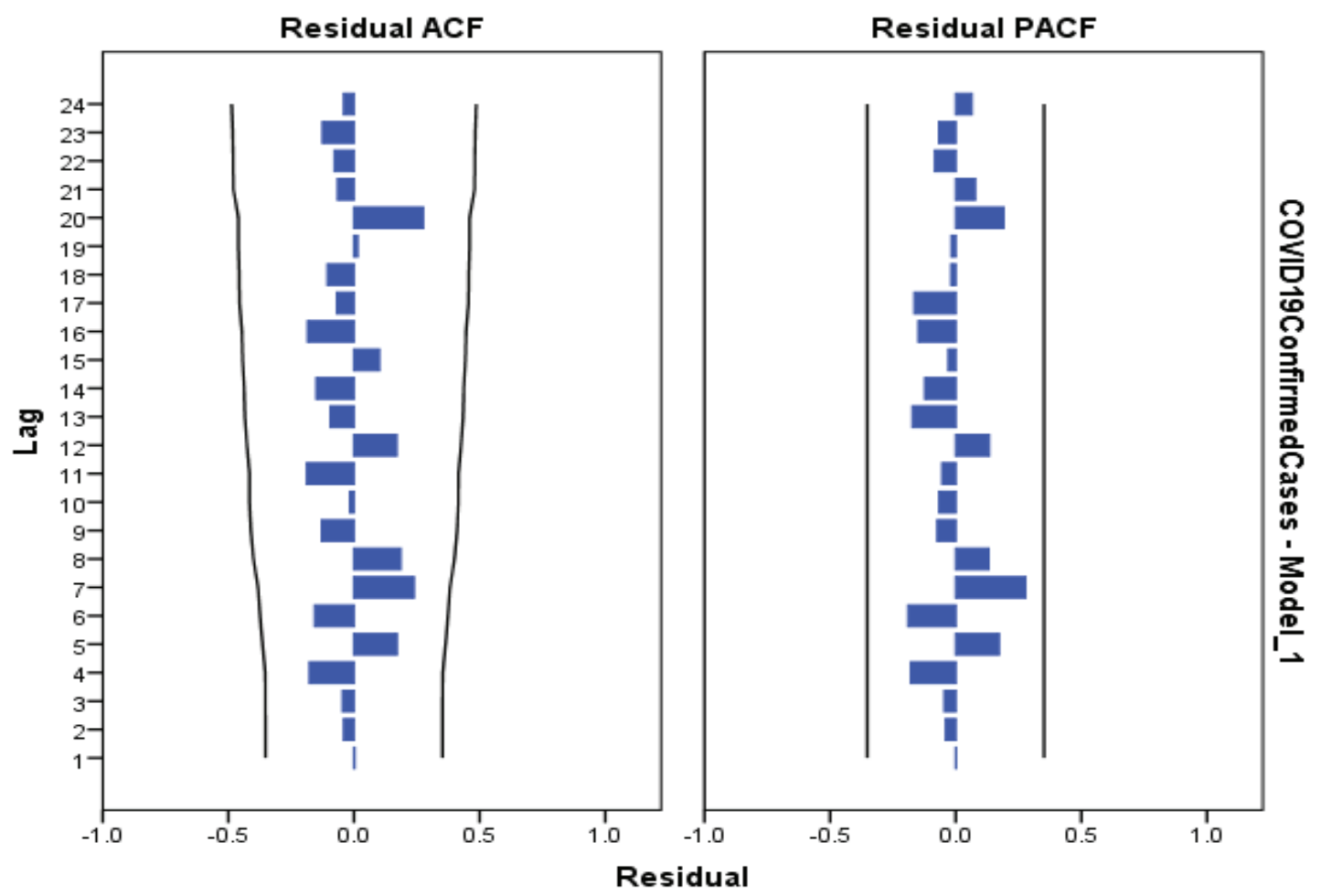

Figure 2. Forecasting COVID-19 confirmed cases in Nepal till 2 June 2020

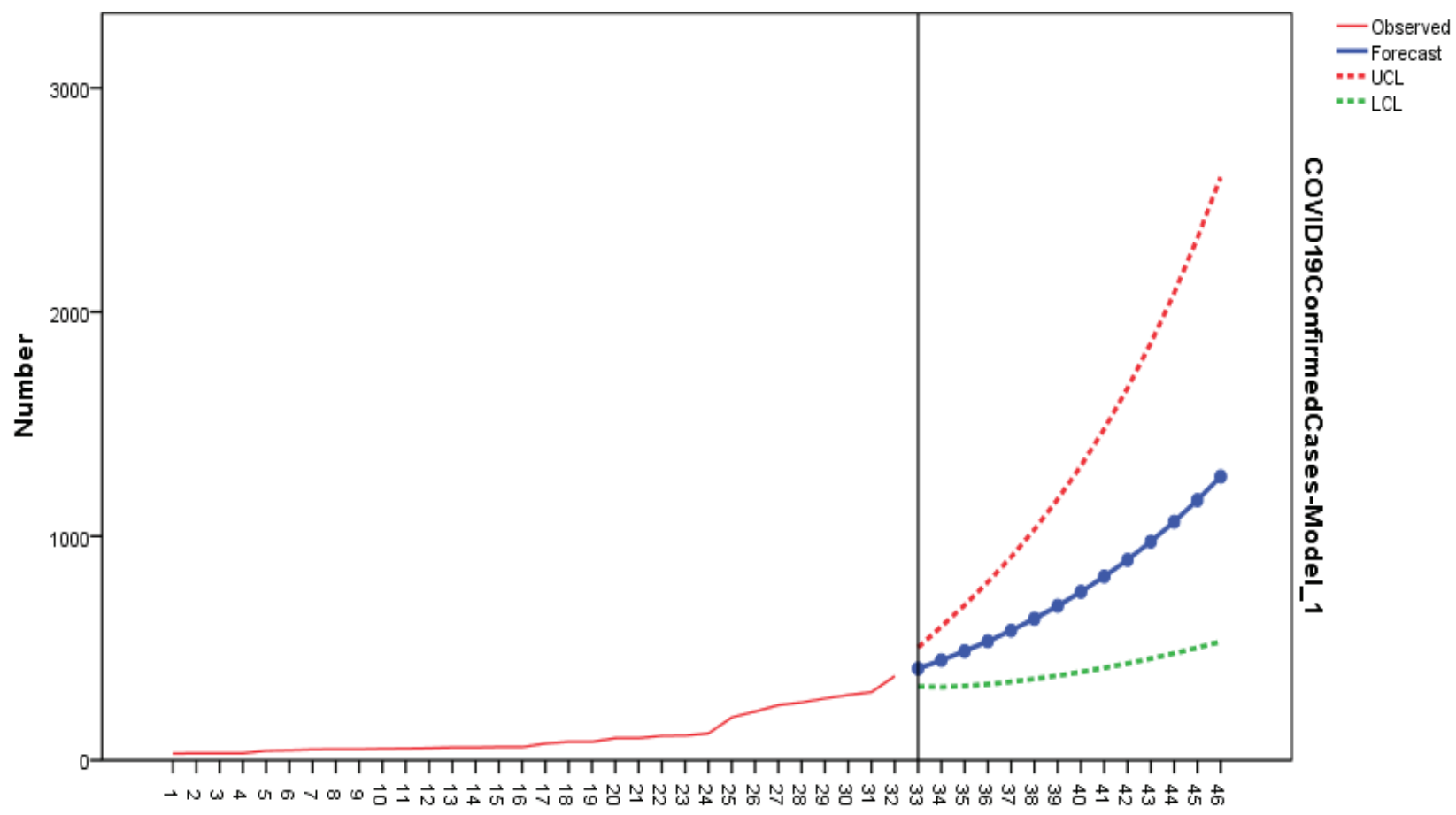

Date 
Figure 3. Comparison of model predicted cases with the observed cases from 18 April to 19 May 2020

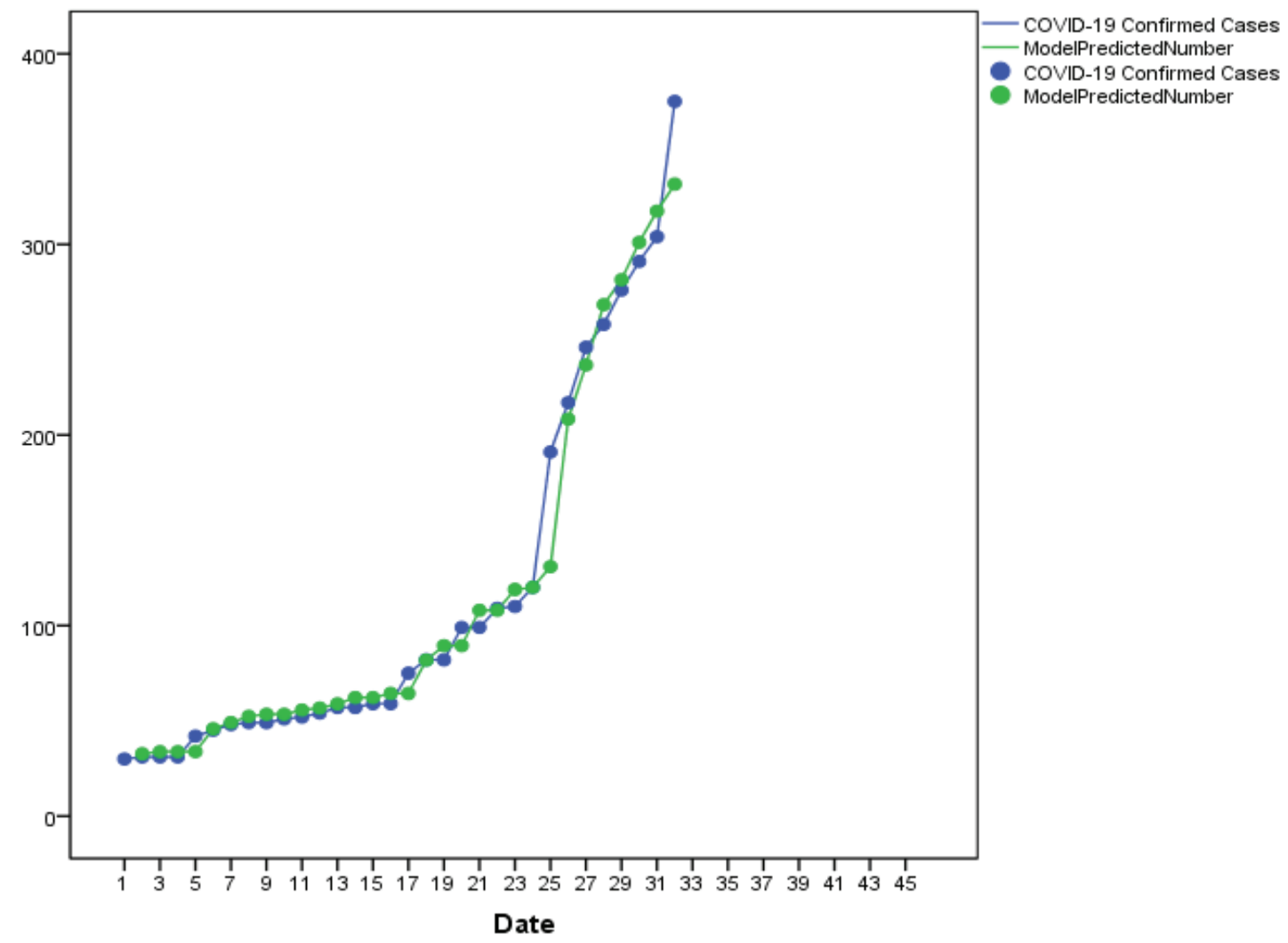

predicted cases and the observed cases from 18 April to 19 May 2020, the period from which input data were gathered. Based on this comparison, the model demonstrates good predictive validity. These observations suggest that the number of COVID-19 cases in Nepal is going to increase consistently over the next two weeks time period. The decision of extending the control measures till the 2 June is much warranted and is consistent with the results from the present time series forecasting study ${ }^{4}$. Even going into the future, administrative decisions must be backed by sound empirical evidence about control of transmission.

\section{REFERENCES}

1. World Health Organization. Coronavirus disease (COVID-19): Situation Report- 120. https://www.who.int/docs/defaultsource/coronaviruse/situation-reports/20200519-covid-19sitrep-120.pdf?sfvrsn=515cabfb_2. Published May 19, 2020. Accessed May 22, 2020.

2. World Health Organization. Coronavirus disease (COVID-19):
Situation Report- 116. https://www.who.int/docs/defaultsource/coronaviruse/situation-reports/20200515-covid-19sitrep-116.pdf?sfvrsn=8dd60956_2. Published May 15, 2020. Accessed May 22, 2020.

3. World Health Organization. Coronavirus disease 2019 (COVID-19) situation reports. https://www.who.int/ emergencies/diseases/novel-coronavirus-2019/situationreports. Accessed May 19, 2020.

4. Poudel A. After second Covid-19 death, government extends lockdown to June 2. The Khatmandu Post. https:// kathmandupost.com/national/2020/05/17/governmentextends-nationwide-lockdown-until-june-2. Published May 17, 2020. Accessed May 19, 2020.
CONFLICTS OF INTEREST

The author has completed and submitted the ICMJE Form for Disclosure of Potential Conflicts of Interest and none was reported.
PROVENANCE AND PEER REVIEW

Not commissioned; internally peer reviewed.

FUNDING

There was no source of funding for this research. 